School of Finance

University of St.Gallen

Who is Changing Health Insurance Coverage? EMPIRICAL EVIDENCE ON POLICYHOLDER DYNAMICS

MaRcus Christiansen

MARTIN ELING

JAN-PHILIPP SCHMIDT

LORENZ ZIRKELBACH

WORKING PAPERS ON FinANCE No. 2012/23

INSTITUT FÜR VERSICHERUNGSWIRTSCHAFT (I.VW - HSG)

DECEMBER 2012 


\title{
WHO IS CHANGING HEALTH INSURANCE COVERAGE? EMPIRICAL EVIDENCE ON POLICYHOLDER DYNAMICS
}

\author{
Marcus C. Christiansen ${ }^{1}$, Martin Eling ${ }^{2}$, Jan-Philipp Schmidt ${ }^{1,3}$, Lorenz Zirkelbach ${ }^{1}$
}

\begin{abstract}
Long-term health insurance contracts provide policyholders with the option of lapsing coverage or switching to another tariff within the same insurance company. We empirically analyze policyholder behavior regarding contract commitment in a large dataset of German private health insurance contracts. We show that short-term as well as long-term premium development, along with premium adjustment frequency, affect lapse and tariff switch rates. Moreover, the sales channel has a strong impact on switching behavior, indicating that policyholder choice is not fully independent of sales representatives. Our results are important for risk assessment and risk management of portfolios of health insurance contracts and provide better understanding of the dynamics of policyholder behavior in health insurance.
\end{abstract}

\section{INTRODUCTION}

In this paper we study policyholder behavior in regard to long-term health insurance. We focus on policyholder options to change insurance coverage. Policyholders may leave their current insurer, thereby lapsing the contract or, alternatively, they may remain with the insurer but choose different coverage at a different tariff. Lapse is often financially irrational. First, most people experience worsening health as they age; therefore, a new policy will likely include a higher risk charge and therefore higher premiums. Second, the accumulated reserves generated from overcharging policyholders in the early years of the contract in order to undercharge them in later years and maintain a level premium are forfeited (Baumann, Meier, and Werding, 2008).

Institute of Insurance Science, University of Ulm, 89069 Ulm, Germany.

Institute of Insurance Economics, University of St. Gallen, 9010 St. Gallen, Switzerland.

Corresponding author, email: jan-philipp.schmidt@uni-ulm.de, phone: +49 7315031171. 
Tariff switch, however, may allow policyholders to avoid being re-classified for underwriting purposes while also allowing them to maintain the accumulated reserves.

In German long-term health insurance contracts, reimbursement of costs charged by physicians and other medical services is contractually fixed until death, lapse, or tariff switch by the policyholder. Pricing of these policies is based on an estimate of health care reimbursements over the entire life of the individual, which is made at the time the policy is purchased based on community risk classifications. ${ }^{4}$ Individuals pay a whole-life level premium so that in the early years of the contract, the part of the level premium exceeding expected reimbursement is accumulated in a reserve and used for higher reimbursement in later contract years. ${ }^{5}$ This health insurance funding approach may be denoted as individual whole-life balancing and it is fundamentally different from the guaranteed renewable short-term health insurance found in other countries (Pauly, Kunreuther, and Hirth, 1995) or from time-consistent health insurance proposed by Cochrane (1995). For further specifics of the German private health insurance system, the reader is referred to Hofmann and Browne (2012).

Lapse may have a severe impact on the insurance company’s financial situation. In other settings, high lapse rates have been shown to cause losses due to unpaid acquisition costs (see, e.g., Kuo, Tsai, and Chen, 2003; Eling and Kiesenbauer, 2012) and to diminish future profits due to a potentially shrinking portfolio. Adverse selection and adverse retention (good risks leave the pool, while only bad risks remain) are likely outcomes of lapse as well, distorting the insurer's competitive position (Altman, Cutler, and Zeckhauser, 1998). An interesting aspect of the German private health insurance system is that high lapse rates (exceeding expected lapse rates) may increase the short-term profit as reserves of lapsed policies in most cases enlarge the annual gross surplus.

Why, then, would policyholders choose to lapse? Goldman, Leibowitz, and Robalino (2004) study policyholder choice across different health insurance plans in U.S. group health insurance. They show empirically that relative premium increases affect policyholder decisions about switching coverage, confirming earlier empirical results for individual health insurance with

4 To compensate for very high expected reimbursements, high-risk policyholders have to pay an additional premium loading on top of the premium based on the community rating.

5 If the portfolio experience of health expenditure is deteriorating, then the health insurance company is allowed to adjust level premiums, as will be discussed in detail later. Moreover, there is a balancing between low risks (health expenditure below portfolio-average health expenditure) and high risks (health expenditure above portfolio-average health expenditure). 
Californian health insurance data (Buchmueller and Feldstein, 1997). Crocker and Moran (2003) provide theoretical and empirical evidence that lapse rates fall (i.e., policyholders have higher policy commitment) when health insurance is bundled with employment contracts. Analyzing European long-term health insurance contracts as part of an insurance bundle, Pinquet, Guillén, and Ayuso (2011) observe immobile policyholders who make financially irrational lapse decisions. Specifically considering German long-term health insurance contracts, Hofmann and Browne (2012) find evidence of both adverse selection and consumer lock-in due to the structure of the insurer's one-sided commitment. ${ }^{6}$

We contribute to this literature by providing a better understanding of factors that affect policyholder behavior in health insurance and the management of long-term health insurance portfolios. For this purpose we analyze a dataset of 180,000 insured persons in the year 2010 using multinomial logistic regression models. We focus on German private health insurance contracts, a long-term product design that involves policyholders entering into lock-in situation after several years of contract duration because of heavy front-loading (comparable to Hendel and Lizzeri, 2003). ${ }^{7}$ Nevertheless, policyholders switch, a phenomenon that motivates this study of policyholder dynamics. Next to analyzing lapse decisions we are also interested in policyholder decisions to increase or decrease insurance coverage. Eight product and policyholder characteristics (age, gender, contract duration, sales channel, premium size, premium development, premium adjustment frequency, individual loss ratio) are analyzed simultaneously in regard to policyholder choice.

Our results support the hypothesis that policyholders holding long-term contracts are sensitive to relative premium changes. Short-term premium increases, however, did not always lead to higher lapse or tariff switch, which is inconsistent with evidence found in the U.S. market (Buchmueller and Feldstein, 1997; Goldman, Leibowitz, and Robalino, 2004). This finding suggests that contract design affects policyholder behavior. Furthermore, our results confirm that the sales channel has a significant impact on policyholder choice. Often, policyholders do not make these

\footnotetext{
6 A broad literature review on choice behavior in health insurance in the United States is presented by Scanlon, Chernew, and Lave (1997).

7 This lock-in situation is also found in the health insurance markets of other countries as well as in other long-term insurance contracts such as life insurance. Thus, our results for German private health insurance are also relevant for other countries and insurance markets. Therefore, our analysis complements the extant literature, particularly that covering health insurance in other countries (e.g., Goldman, Leibowitz, and Robalino, 2004; Pinquet, Guillén, and Ayuso, 2011) and life insurance (e.g., Kuo, Tsai, and Chen, 2003; Eling and Kiesenbauer, 2012).
} 
decisions without contacting sales representatives, that is, they rely to some extent on salesperson recommendations.

The paper continues with the development of seven hypotheses. This is followed by a description of the analyzed data and the applied research methodology. The empirical results are presented and discussed, followed by a conclusion.

\section{HYPOTHESES DEVELOPMENT}

Economic theory implies that demand for health insurance coverage is linked to price of the contract (or, equivalently, the premium). We expect that people enrolled in health insurance are price-sensitive, that is, decisions about policy continuation depend, at least to some extent, on the price of insurance (Feldman et al., 1989; Scanlon, Chernew, and Lave, 1997). The relative price change, that is, individual premium development, allows an analysis of the price-sensitivity of customers of long-term health insurance. Thus, increasing (decreasing) premiums would induce higher (lower) lapse rates. This would be consistent with findings from U.S. data and experience with U.S. health insurance policy design (Buchmueller and Feldstein, 1997; Goldman, Leibowitz, and Robalino, 2004). Policyholder choice may also depend on the existence of alternatives in the health insurance market. If a considered contract with strongly increasing premiums still offers high utility compared to alternative tariffs from competitors (lapse) or the same company (tariff switch), the policyholder will most likely stick with the policy. ${ }^{8}$ Controlling market alternatives is impossible in the considered research design: market alternatives are always contract specific and their details are not available (this methodological problem is also mentioned by Scanlon, Chernew, and Lave, 1997). Based on the price-sensitivity argument, we derive our first hypothesis:

H1: An increasing/decreasing health insurance premium increases/decreases lapse rates and tariff switching.

Premium adjustments in health insurance garner a lot of attention in media. Even if a premium adjustment may be actuarially required to cover higher expected future health expenditure, health insurance companies try to avoid a high number of premium adjustments. Policyholders reassess their coverage if they are contacted by the insurance company (Cutler, Lincoln, and Zeckhauser,

8 Given the lock-in situation, the lapse rate should reflect a tradeoff between the price change and the front loading. Since the front loading is an increasing function of contract age, we should identify an interaction between contract age, price change, and lapse rates. We analyze such interactions in Section 4.2. 
2010). Policyholders check their health insurance needs and assess their satisfaction with the contract. Consequently, lapse or tariff switch might be more likely. Health insurance companies fear the impact of lapse or reduction in insurance coverage on profits because high lapse and reduction rates might, in the long-term, be financially disadvantageous due to the loss of future profits. Furthermore, a shrinking portfolio of health insurance contracts is exposed to the risk of a "death spiral," that is, only the low risks lapse, and thus the portfolio mostly contains the high risks who will need to be charged increasing and unaffordable premiums (Cutler and Zeckhauser, 2000). The second hypothesis is thus:

H2: The number of premium adjustments is positively correlated with lapse and tariff switch behavior.

The intermediation process at underwriting has significant consequences for policyholder decisions throughout the entire contract term. A health insurance contract is usually sold by a sales representative of the insurance company. In our dataset, the sales channel is binary, either a tied agent or a broker. In case of dissatisfaction with the contract, some policyholders consult their sales representative again. As tied agents only sell their own company's products, a lapse is less likely than a tariff switch. Our third hypothesis is thus:

H3: Contracts generated from the tied agent sales channel are less likely to be lapsed than contracts sold by brokers. The effects for tariff switching are reversed.

Recently, some authors have remarked that a policyholder's decision on contract continuation depends on his or her personal wealth situation (e.g., Davidoff, 2009; Pinquet, Guillén, and Ayuso, 2011). Studies on long-term care products, which are similar in design to German private health insurance, are especially likely to show evidence that decisions are linked to personal wealth. It is conjectured that policyholders with less income or a problematic private situation (e.g., unemployment) more frequently lapse their health insurance policy. ${ }^{9}$

Due to legal restrictions, portfolios of German private health insurance companies are predominantly composed of wealthy policyholders and self-employed persons (in our analysis we exclude civil servants and children). This group may be divided into a very wealthy group and a

9 In the life insurance sector, this is known as the "emergency fund hypothesis” (see Kuo, Tsai, and Chen, 2003; Eling and Kiesenbauer, 2012). In life insurance, there is the additional incentive to receive a surrender value, which is not the case in health insurance for contracts written previous to January 1, 2009. The emergency fund hypothesis, however, also posits that another reason people may lapse their life insurance policies is because they are no longer able to pay the premiums. 
less wealthy group. In our analysis, this distinction is only partly possible since we consider premium size as a proxy for the wealth situation. Premium size chiefly depends on the details of coverage (size of deductibles, breadth of treatment, special services, etc.), but also on age at underwriting and health history before underwriting so that wealth is only partly reflected by size of coverage. We assume, however, that the size of the premium (in relation to the average premium in each age group) to some extent reflects the wealth situation as, in general, only very wealthy policyholders can buy high coverage and, thus, the very expensive products. Very wealthy policyholders less frequently need to adjust insurance coverage to their financial situation compared to less wealthy policyholders. We conjecture as fourth hypothesis:

H4: The premium size is negatively correlated with lapse and switching tariff rates.

Due to asymmetric information, insurance companies might be in danger of adverse selection, that is, the tendency of high risks applying for more generous insurance coverage (Rothschild and Stiglitz, 1976). In health economics, several studies empirically confirm the existence of a relationship between policyholder behavior, the price of health insurance coverage, and health status (e.g., Cutler and Reber, 1998), indicating the presence of adverse selection in health insurance. Health insurance companies perform a risk assessment at the time of underwriting. Since the premium is determined on an individual basis, high risks might fear a premium loading designed to cover above-average benefits, which might lessen the danger of adverse selection for the portfolios under consideration.

Altman, Cutler, and Zeckhauser (1998) introduce in an analog fashion to adverse selection the notion of adverse retention, that is, high-risk policyholders continue to maintain generous health insurance coverage whereas low-risk policyholders search the market for cheaper health insurance. The authors elaborate that this immobility of high-risk policyholders is problematic for the risk-type composition of a health insurance portfolio. Moreover, they quantify the effect of adverse retention in relation to adverse selection.

Adverse selection and adverse retention can result in the above-mentioned "death spiral” (Cutler and Zeckhauser, 2000). Increasing switching out of a health insurance portfolio by low-risk policyholders could upset the overall premium-benefit balance. In consequence, a health insurance tariff could be statutorily required to increase premiums due to its more high-risk portfolio structure. In turn, this could trigger even more switching by low-risk types, spurring a spiral and downsizing the portfolio such that only high-risk types remain insured with the 
portfolio. Not all studies on adverse selection in health insurance find death spirals to be relevant. For instance, Pauly, Mitchell, and Zeng (2007) argue that diminishing portfolios may be the result of outdated product design.

In German private health insurance, classification of the policyholder's health status is fixed at the time of underwriting and locked-in for the entire life of the contract. An individual's deteriorating health status does not influence his or her premium schedule. However, lapse behavior is affected by health status in that, in general, a high risk has to pay a higher premium than a low risk when applying for a contract with another health insurance company. Potentially there exists the risk of a death spiral as well.

Similarly to lapse behavior, tariff switching is affected by health care utilization, that is, policyholders with only a few small claims are more likely to adjust their insurance policy to varying needs. The risk type of the policyholder is controlled by the individual claims ratio, that is, the individual annual reimbursement in the previous year in relation to the monthly premium. We hypothesize:

H5: Low-risk-type policyholders more frequently lapse health insurance coverage or switch tariffs.

Health insurance policyholder behavior is significantly influenced by the age and the seniority in the portfolio (e.g., Cutler, Lincoln, and Zeckhauser, 2010). Most policyholders in German private health insurance face the same disadvantage found for Spanish customers in work by Pinquet, Guillén and Ayuso (2011) because in most of the contracts of healthy policyholders, losses due to lapse increase with longer portfolio affiliation.

In a similar way, age is expected to affect lapse rates. A lapse at a higher age (which is strongly correlated with a higher seniority in the portfolio) results in a significant financial loss of the accumulated reserves and rights. Only for policyholders with excellent health histories will the choice of a different health insurance company or different health insurance tariff offer the opportunity to increase utility.

Moreover, lapse rates for each age (based on a univariate analysis) are part of the actuarial calculation of level premiums and reserves. Overall lapse rates decrease with increasing age of the policyholder. 
We expect that policyholders at retirement age are more likely to switch insurance coverage (by a tariff switch) in order to adjust to current needs. Lapse at this age is not an option due to the aforementioned lock-in situation. We thus hypothesize:

H6: The age and the seniority of a policyholder in a health insurance portfolio are negatively correlated with lapse behavior. Tariff switching is positively correlated with age and seniority.

In life insurance, switching behavior depends to some extent on policyholder gender. Some studies reveal that female policyholders are less likely to lapse an insurance contract (Kagraoka, 2005; Eling and Kiesenbauer, 2012). It is argued that this finding is due to women's higher risk aversion and lower income. Actuaries consider differences in historical lapse behavior of male and female policyholders when calculating the premium and reserve. Thus, we hypothesize that lapse and tariff switch vary depending on policyholder gender. The final hypothesis is:

H7: Lapse and tariff switch behavior depend on the gender of the policyholder.

\section{Data AND Modeling Framework}

We analyze data of a large German private health insurance company. Our dataset includes data on about 180,000 insured persons who have at least a substitutive whole-life health insurance contract. These contracts were in force on January $1,2010 .{ }^{10}$ Table 1 describes the product and individual characteristics under consideration. Given that we are considering a proportional response among more than two options that are categorical rather than relative (the proportion of the insured sample set that switches by either lapse or tariff or does not switch, and for those who do switch, the direction of the switch), we use a multinomial logistic regression for our analysis. In this setting, independent variables can be real valued, binary valued, categorically valued, and so forth. The complex structure of the relationships between the various independent variables and the dependent variable, however, leads us to use categorical independent variables. Doing so allows us to proceed forward without having to make assumptions on the functional relationship between the dependent and independent variables. Furthermore, the interpretation of results is much clearer than it would be if we used real-valued independent variables. Therefore, all characteristics are categorized into homogeneous groups in the sense that (a) groups have a

\footnotetext{
10 Substitutive health insurance contracts substitute for statutory health insurance contracts, that is, they offer at least the insurance coverage of statutory health insurance. We restrict the data (entire dataset of the insurer) to non-civil servants. Civil servant policyholders' behavior is affected to a large extent by many special civil servant laws.
} 
similar exposure and (b) lapse and tariff switch rates are similar in each group based on a univariate analysis.

Age: Policyholders are grouped into five categories. All policyholders older than 60 are sorted into a large group of "old" policyholders. This procedure is motivated by the fact that in this age group, lapse is very unlikely due to two reasons: (a) it is financially unattractive due to usually higher reserves at higher ages that are lost in case of lapse and (b) due to deteriorating health conditions, policyholder are likely to face re-classification of their risk at another health insurance company. Moreover, we do not consider insurance contracts held by persons younger than age 21 as contract continuation decisions for this group most likely are made by parents. In the remaining dataset, almost all the insured persons are also the policyholders.

Table 1: Overview of Policyholder and Product Characteristics and Categories (categories in italic)

- Age: $(20,30],(30,40],(40,50],(50,60],(60,110]$

- Gender: Female, Male

- Contract duration: $(5,10],(10,15],(15,20],(20,25],(25,100]$

- Sales channel: Tied agent, Broker

- Premium size: Low, Average, High

- Premium development (short-term and long-term): Strongly decreasing, Decreasing, Stable, Increasing, Strongly increasing

- Premium adjustment frequency: Low, Medium, High

- Individual loss ratio: No claims ever, No claims (previous year), Low claims, Medium claims, High claims, Very high claims

Contract duration: Contract duration is also sorted into five categories. We restrict the dataset to policyholders with a portfolio affiliation longer than five years. An early lapse (i.e., earlier than five years' contract duration) is affected by several legal restrictions. For example, lapse is prohibited during the first two years of the contract.

Sales channel: The sales channel variable controls for the intermediation of the health insurance contract. The company employs tied agents and brokers.

Premium size: Each policyholder's premium is scaled with respect to the monthly premium average of the corresponding age group. Low contains policyholders with a monthly premium 
lower than $80 \%$ of the average premium, whereas policyholders in the category High pay monthly premiums that are above $120 \%$ of the average premium.

Premium development: We measure short-term individual premium development with a relative comparison between the monthly premium in 2010 and the monthly premium in 2009. Long-term premium development is calculated as the geometric average of premium development from 2006 to 2010. If the premium has not varied more than 5\%, then the premium development is Stable, deviations of 5\% to $20 \%$ are Increasing/Decreasing, and deviations of more than $20 \%$ are denoted Strongly increasing/Strongly decreasing.

Premium adjustment frequency: This is the absolute number of premium adjustments during the past five years. Low represents contracts with fewer than three premium adjustments. Medium covers contracts with three to five adjustments and premiums that have been adjusted more than five times in the past five years are put in the High category. A policyholder may face more than one adjustment a year if his or her coverage is separated into more than one contract. ${ }^{11}$

Individual loss ratio: Every policyholder has an individual claim experience in 2009. We relate the individual claim experience to the monthly premiums of 2009. No claim experience ever contains all those policyholders with no claims ever. No claims 2009 consists of policyholders without a claim in 2009, but at least one claim in earlier years of the policy. Low claims to very high claims denote policyholders with at least one claim in 2009. Low claims consists of policyholders with reimbursement up to 1.5 times the monthly premium; Medium claims consists of policyholders with reimbursements from 1.5 to 6 times the monthly premium; High claims consists of policyholders with reimbursements from 6 to 12 times the monthly premium; and Very high claims consists of policyholders who received reimbursements of more than the annual premium.

In Germany, long-term health insurance lapse has two possible outcomes for the policyholder. If the policyholder still meets the eligibility criteria for substitutive private health insurance coverage, a contract with another private insurance company may be signed. If policyholders satisfy certain strict social legislation requirements (e.g. if the income is falling short of the annual limit for non civil servants) and if they are less than age 56, they may be eligible for the

11 Coverage may be separated into several contracts, so that one policyholder has, for instance, three contracts, with one covering outpatient treatment, one covering inpatient treatment, and one covering dental treatment. 
statutory health insurance system. A tariff switch also results in a dichotomous outcome: The policyholder decides either to increase or decrease health insurance coverage.

With multinomial logistic regression models we analyze the impact of all policyholder and all product characteristics simultaneously (see, e.g., Nelder and Wedderburn, 1972; McFadden, 1981). We employ two distinct models: one to analyze lapse behavior and one to analyze tariff switch behavior. In both models we use the same categories for covariates to make the results of lapse and tariff switch comparable. The multinomial response variable allows distinguishing between the reasons behind policyholder decisions on contract continuation.

The model for our lapse analysis distinguishes between three alternatives in a policyholder's decision: lapse and switch to another private health insurance company ("lapse"); lapse and switch to statutory health insurance ("statutory lapse”); and continue the policy ("no lapse.”). The majority of the contracts are not lapsed. The average rates are 1.5\% for "lapse," $1.1 \%$ for “statutory lapse,” and 97.4\% for “no lapse.” During 2010, each policyholder had the choice to switch the tariff and increase insurance coverage ("increasing”). Moreover, a tariff switch and a decrease in insurance coverage (“decreasing”) was also possible. And, of course, each individual can make the choice not to switch ("no tariff switch"). Similar to lapse, tariff switching is a rare event in the portfolio. On average, we observe $0.6 \%$ for “increasing coverage," $3.6 \%$ for “decreasing coverage,” and 95.8\% for “no tariff switch.”

In our multinomial logistic regression model, the logarithm of the odds of the possible outcomes (lapse model: lapse, statutory lapse, no lapse; tariff switch model: increasing, decreasing, no tariff switch) is assumed to depend linearly on the covariates. Each covariate is modeled by several categories (0/1 coding); for each category of the covariates we estimate its impact on the outcome. The regression allows us to quantify the effect of each covariate on the decision regarding lapse (lapse model) or tariff switch (tariff switch model) separately. We present odds ratios for each covariate, that is, the effect of the category of a covariate on the dependent variable (always with respect to a specified reference category of the covariate). The multinomial logistic regression is a standard method for quantifying the probabilities of different outcomes and is employed in health economics literature on choice decisions (see, e.g., Goldman, Leibowitz, and Robalino, 2004; Pauly, Mitchell, and Zeng, 2007).

Recent analyses of policyholder behavior use models from survival analysis to quantify the effects of several characteristics on lapse. For instance, Eling and Kiesenbauer (2012) and 
Pinquet, Guillén and Ayuso (2011) apply proportional hazard models. Models from survival analysis are appropriate for multi-year datasets, especially if the time until lapse or tariff switch is known for a longer period of time (which is not the case for our dataset). In testing our hypotheses from Section 2 we favor the multinomial logistic regression over other data mining algorithms (e.g., non-parametric approaches such as decision trees; see Viaene et al., 2002) mainly due to its simple probabilistic interpretation of the estimated parameters.

\section{Results}

We present results for two model specifications. The results of a basis model without interactions are discussed in Section 4.1. The results of model extensions including interactions between different characteristics are presented in Section 4.2.

\subsection{MOdel Without INTERACTION}

The odds effects of the two models are presented in Table 2. The odds effect quantifies the effect of the corresponding covariate on the lapse and tariff switch behavior with respect to the reference level; for example, an odds effect of 1.2 indicates that the corresponding variable increases the lapse chance by $20 \%$ ceteris paribus. We find each covariate to be significant in at least one of the two models.

\section{Premium Development Hypothesis (H1)}

The results indicate that if premiums rise during the previous five years (long-term perspective), lapse rates increase significantly compared to the lapse rates of policyholders enjoying stable premiums. We obtain similar results for a short-term perspective of one year. However, strongly increasing premium development in the short-term does not intensify lapses, indicating that the long-term development is more relevant with respect to contract commitment. Apparently, policyholders in the considered portfolio are price-sensitive, that is, their decisions on policy continuation are related to an increasing premium development. This is in line with Cutler, Lincoln, and Zeckhauser (2010), who find that changes in the premium cause people to reassess their health insurance coverage. Policyholders are aware of premium increases in the past and how this expense has risen over time. We conclude that policyholders take negative long-term premium experience into account when making policy continuation decisions.

The observation of mobile policyholders also may result from the fact that the health insurance company under consideration raised premiums more than competing health insurance companies 
in the market (Scanlon, Chernew, and Lave, 1997). In this case the policyholders do not reward the insurance company with higher portfolio commitment because premium increases always negatively influence the individual income situation. The odds ratios for a statutory lapse are significantly different from those for a regular lapse. Strongly increasing premium development (short-term as well as long-term) predominantly increases the chance of statutory lapse. Thus, increasing premiums are especially problematic for the less wealthy part of the portfolio.

In the long-term perspective we only find weak evidence that a decreasing premium development reflects price-sensitivity: Policyholders experiencing a premium decrease are less mobile; they continue to be insured by the insurance company. The benefits from a health insurance contract are not reduced by the insurance company because all benefits are contractually fixed in the underwriting process. In general, there are two ways a premium can be decreased: (a) the policyholder decides on lower coverage or (b) the insurance company uses profits and reserves to provide premium relief. In this analysis, the policyholders behave as expected: they reward the insurance company with high loyalty if the premium decreases.

In the short-term, however, we observe the opposite effect: A short-term premium decrease intensifies lapse rates; the lapse odds increased by $47.3 \%$ for decreasing short-term premium experience compared to stable premium development. A possible explanation for this is that a policyholder achieves a lower premium by voluntarily reducing coverage. Perhaps the individual experienced unemployment or some other hardship. In the succeeding year, this individual may not be able to afford the coverage or may no longer meet the eligibility criteria and therefore coverage is lapsed. This scenario is similar to "the emergency fund hypothesis" in the life insurance literature in which policyholders lapse coverage because of a financial emergency. In contrast with life insurance, however, lapse of a long-term health insurance policy does not provide the policyholder with funds via surrender value. Instead, the best the policyholder can achieve is cheaper health insurance with potentially less coverage. 
Table 2: Results of the Multinomial Logistic Regression Models — Odds Effects

\begin{tabular}{|c|c|c|c|c|c|c|}
\hline & & & \multicolumn{2}{|c|}{ Lapse Model } & \multicolumn{2}{|c|}{ Tariff Switch Model } \\
\hline & & & Lapse & Statutory Lapse & Increase & Decrease \\
\hline \multirow[t]{10}{*}{ H1 } & Premium & Strongly decreasing & 1.009 & $2.889 *$ & 1.172 & $0.354 *$ \\
\hline & Development & Decreasing & 0.760 & 1.040 & $1.482 *$ & $0.676 * *$ \\
\hline & (long-term) & Stable (Reference) & & & & \\
\hline & & Increasing & $1.146 *$ & 1.012 & $0.837 *$ & 0.963 \\
\hline & & Strongly increasing & $1.359 *$ & $2.054 * *$ & $2.035 * *$ & $1.675 * *$ \\
\hline & Premium & Strongly decreasing & 0.839 & $1.579 *$ & $0.317 * *$ & 0.885 \\
\hline & Development & Decreasing & $1.473 *$ & $1.963 * *$ & $0.418 *$ & $1.311 * *$ \\
\hline & (short-term) & Stable (Reference) & & & & \\
\hline & & Increasing & $1.135 *$ & 1.122 & $0.789 *$ & $1.077 *$ \\
\hline & & Strongly increasing & 0.872 & $1.302 *$ & $0.474 * *$ & 1.109 \\
\hline \multirow[t]{3}{*}{ H2 } & Number of & Low & $1.624 *$ & 0.854 & $1.554 *$ & $0.734 *$ \\
\hline & Premium & Average (Reference) & & & & \\
\hline & Adjus tments & High & 0.930 & 1.005 & 0.970 & $1.284 * *$ \\
\hline \multirow[t]{2}{*}{ H3 } & Sales & Tied agent (Reference) & & & & \\
\hline & Channel & Broker & $1.525 * *$ & $1.341 * *$ & $0.465 * *$ & $0.728 * *$ \\
\hline \multirow[t]{3}{*}{ H4 } & Premium & Low & 1.069 & $1.440 * *$ & $1.938 * *$ & $0.609 * *$ \\
\hline & Size & Average (Reference) & & & & \\
\hline & & High & 0.915 & $0.780 *$ & $0.821 *$ & $1.061 *$ \\
\hline \multirow[t]{6}{*}{ H5 } & Individual & No claims (Reference) & & & & \\
\hline & Loss Ratio & No claims (prev. year) & $0.804 *$ & 0.863 & $1.820 *$ & $1.644 * *$ \\
\hline & & Low claims & 0.892 & 0.891 & $1.553 *$ & $1.847 * *$ \\
\hline & & Average claims & $0.698 * *$ & 0.812 & $1.548 *$ & $1.610 * *$ \\
\hline & & High claims & $0.556 * *$ & 0.873 & 1.326 & $1.526 * *$ \\
\hline & & Very high claims & $0.524 * *$ & 0.877 & $1.624 *$ & $1.343 *$ \\
\hline \multirow[t]{10}{*}{ H6 } & Age & (20,30] (Reference) & & & & \\
\hline & & $(30,40]$ & $0.736 *$ & $0.209 * *$ & 1.057 & $0.281 * *$ \\
\hline & & $(40,50]$ & $0.589 * *$ & $0.171 * *$ & $0.629 *$ & $0.277 * *$ \\
\hline & & $(50,60]$ & $0.523 * *$ & $0.141 * *$ & $0.457 * *$ & $0.366 * *$ \\
\hline & & $(60,110]$ & $0.181 * *$ & $0.028 * *$ & $0.179 * *$ & $0.363 * *$ \\
\hline & Duration & (5,10] (Reference) & & & & \\
\hline & & $(10,15]$ & $0.659 * *$ & $0.850 *$ & 0.849 & $1.197 * *$ \\
\hline & & $(15,20]$ & $0.501 * *$ & $0.558 * *$ & 1.075 & $1.251 * *$ \\
\hline & & $(20,25]$ & $0.409 * *$ & $0.572 * *$ & 0.883 & $1.195 * *$ \\
\hline & & $(25,100]$ & $0.284 * *$ & $0.346 * *$ & 0.969 & $0.884 *$ \\
\hline \multirow[t]{2}{*}{ H7 } & Gender & Male (Reference) & & & & \\
\hline & & Female & $1.182 *$ & $1.776 * *$ & 0.899 & 0.993 \\
\hline
\end{tabular}

Note: Significance level for the Wald test of corresponding coefficients: ** indicates a p-value less than 0.01 ; * indicates a p-value between 0.01 and 0.05 . Pseudo- $\mathrm{R}^{2}: 0.023$ (lapse) and 0.012 (tariff switch). 
The data for lapse and consequent switch to the statutory health insurance system ("statutory lapse”) support this hypothesis. Lapse chances increase following a premium decrease for both short-term and long-term development, with a stronger relationship in the case of short-term development. This has important implications for the management of health insurance companies: Contracts with decreasing premium have a higher risk of lapse, especially if clients are voluntarily reducing coverage.

Results for the tariff switching model also reveal policyholder sensitivity to premium development. Here, increasing premiums mainly boost tariff switching behavior. Strongly increasing premiums (in the long-term) and increasing premiums (in the short-term) intensify switching, with the result of decreasing insurance coverage. In the case of an increasing premium development (short-term as well as long-term), the likelihood of tariff switch to increasing coverage declines (an exception is a strongly increasing premium in the long-term). As expected, a long-term decreasing development lessens the chance that policyholders will opt for reduced coverage, whereas the chances of choosing higher coverage increase. To sum up, premium developments affect policyholder choice in regard to tariffs.

Number of Premium Adjustments Hypothesis (H2)

Our empirical findings do not support the hypothesis that a high number of premium adjustments results in increasing lapse behavior. The observed results even reflect opposite effects. In our sample, policyholders experiencing only a few premium adjustments had significantly higher lapse rates than the rest of the portfolio.

The result indicates that policyholders in Germany are used to premium adjustments and do not penalize the company for them by lapsing. However, such a result might be due to the absence of alternatives: if policyholders do not expect stable premiums from any other health insurance company, lapsing their current contract would hold no advantage.

The results for tariff switch are more intuitive: the chance of reducing (increasing) health insurance coverage via a tariff switch increases (decreases) along with the absolute number of premium adjustments. If there are only a few premium adjustments, the likelihood of choosing increased health insurance coverage increases significantly. 
Sales Channel Hypothesis (H3)

Prior literature demonstrates that low lapse rates for long-term products are the result of insufficient knowledge about insurance products (Pinquet, Guillén and Ayuso, 2011). The sales channel effect is one point here. We find that contracts purchased from tied agents are less likely to lapse. This is not surprising when we remember that tied agents can offer only own-company products, and thus provide few alternative options for the policyholder. If the policyholder fully trusts his or her financial advisor, a lapse is less likely. Brokers, on the other hand, can usually choose from a wide array of insurance providers, are thus using a broker is more conducive to lapse behavior than switching behavior.

Another implication of these results is that policyholders rely on salespersons for advice, possible due to insufficient knowledge of the mechanisms of health insurance in Germany. However, there is no data available to control for this hypothesis.

The literature on intermediation in the insurance industry suggests that brokers may provide better service to policyholders than can be provide by tied agents due to a higher information level (product quality hypothesis; e.g., Trigo-Gamarra, 2008; Eckardt and Räthke-Döppner, 2010). If the observed lapse decision always results in an advantage for the policyholder, then our empirical results of higher lapse likelihood when the contract is secured through a broker instead of from a tied agent would strongly support the product quality hypothesis. Our data do not allow such an analysis, as such would require specific health and wealth information for each policyholder.

The odds effects for the tariff switch show that tariff switch is less likely in the case of contracts sold by brokers compared to those brought from tied agents. Again this is explained by the fewer alternatives offered by tied agents. However, a tariff switch allows policyholders to retain acquired rights and reserves.

\section{Premium Size Hypothesis (H4)}

We find no evidence that the size of the premium in relation to the average premium is a main determinant of lapse. We suspect that our sample is comprised of policyholders with relatively homogenous wealth status and therefore we are unable to test as effectively for this factor as would be possible with a more heterogeneous portfolio. 
We also investigate the case of lapse and consequent switch to the statutory health insurance system ("statutory lapse”). Chance of lapse decreases significantly for higher premiums, which may be due to the legal restriction that annual income has to exceed a certain level before policyholders with a regular employment may apply for private health insurance. Only policyholders with an income falling short of the annual limit, age below 56, and satisfying social legislation rules may switch to the statutory system. This idea is supported by an analysis of the premium development. Strong premium increases (short-term as well as long-term) induce higher lapses to the statutory health insurance system because the new premium is often no longer affordable, meaning that lapse to the statutory health insurance system is a financially advantageous course of action.

Premium size also influences tariff switching behavior. The size of the premium is positively correlated with the chance of reducing insurance coverage. Policyholders may no longer be able to afford the high premium and so they reduce insurance coverage via a tariff switch (e.g., agreeing to a higher deductible). Reciprocally, a policyholder with a high premium is less likely to increase insurance coverage via a tariff switch. In some cases, the high premium is due to maximal coverage. Thus, the size of the premium is negatively correlated with the chance of increasing insurance coverage.

\section{Individual Loss Ratio Hypothesis (H5)}

We find that higher claim ratios result in significantly lower lapse rates. That is, the chance of lapse almost halves if policyholders suffered severe claims during the previous year. If we consider the individual claim ratio as an estimate for future health expenditures, our results are in accordance with those of Hofmann and Browne (2012) as well as with a study of Dutch health insurance data (Van den Berg et al., 2008). These authors observe the same negative correlation between health expenditure and switching behavior. In the health economics literature, authors refer to the lower switching rates of less healthy policyholder as adverse selection and adverse retention (Altman, Cutler, and Zeckhauser, 1998; Cutler, Lincoln, and Zeckhauser, 2010). We are not able to assess whether the entire portfolio is suffering from adverse retention as we have no information about new business or the company's underwriting policy. A steady admission of young and healthy policyholders would lower the impact of adverse retention.

The effects for the individual loss ratio also support a hypothesis presented in Pinquet, Guillén and Ayuso (2011): lapsing policyholders are usually in better health. In our data, we are able to 
identify policyholders who have never made a claim during the life of the contract (reference category in the "individual loss ratio" category). Those policyholders have a significantly higher chance of lapsing than do policyholders with high claims in relation to the premium during the previous year.

However, this trend in lapse does not hold for statutory lapse. Whether a policyholder chooses the lapse option to the statutory system is independent of individual claim history.

Tariff switching is more likely for policyholders who have received at least one reimbursement from the health insurance company. There is no trend for increasing insurance coverage. However, tariff switch to reduced coverage is negatively correlated with the individual loss ratio (for those policyholders having at least one claim in the previous year).

To sum up, policyholders are less likely to lapse or reduce insurance coverage if they utilized health insurance benefits in the previous year. Thus, policyholders with no claims have a higher risk of lapse.

Age and Duration Hypothesis (H6)

After age 60, long-term health insurance lapse is rare. In contrast, young policyholders are more mobile in this regard and tend to adapt their health insurance to their needs and health history. This confirms the results from Strombom, Buchmueller, and Feldstein (2002) and Van den Berg et al. (2008), all of whom claim that young clients are more price-sensitive, with the consequence that higher lapse rates are observed in this customer group.

Our results reflect the lock-in situation of older policyholders: a lapse after age 60 is very unlikely. Lapse rates in our sample decrease with increasing age. This is consistent with the conjectured relationship between age and lapse. Moreover, we observe that the effects for statutory lapse are even higher than the effects for voluntary lapse, reflecting that it is almost impossible to switch back to the statutory system after age 55. The analysis of seniority in the portfolio indicates similar results.

Analysis of tariff switching, however, reveals different results. For policyholders between the ages of 30 and 40, the decision to tariff switch, with consequent increasing coverage, peaks. Presumably, policyholders in this age group more often review the original health insurance coverage and adjust their insurance contract to higher coverage. Compared to the reference age group, the chance of reducing insurance coverage drops significantly after age 30. 
Table 3: Summary of Empirical Results Compared to Existing Literature

\begin{tabular}{|c|c|c|}
\hline Hypothesis & Main Results & Existing Literature \\
\hline $\begin{array}{l}\text { H1: Premium } \\
\text { Development }\end{array}$ & $\begin{array}{l}\text { Price-sensitive policyholders: long- } \\
\text { term premium increase results in } \\
\text { higher lapse rates; short-term } \\
\text { premium decrease may be followed } \\
\text { by a lapse or statutory lapse }\end{array}$ & $\begin{array}{l}\text { Overall consistent with price- } \\
\text { sensitivity found by Cutler, Lincoln, } \\
\text { and Zeckhauser (2010) }\end{array}$ \\
\hline $\begin{array}{l}\text { H2: Number of } \\
\text { Premium Adjustments }\end{array}$ & $\begin{array}{l}\text { Lapse higher in case of fewer } \\
\text { premium adjustments; effect for } \\
\text { tariff switch with decreasing } \\
\text { coverage reversed }\end{array}$ & Not considered in existing literature \\
\hline H3: Sales Channel & $\begin{array}{l}\text { Lapse higher for brokers, lower for } \\
\text { tied agents; effects reversed for tariff } \\
\text { switch rates }\end{array}$ & $\begin{array}{l}\text { Results for lapse in line with results } \\
\text { for life insurance (Eling and } \\
\text { Kiesenbauer, 2012); tariff switch } \\
\text { not considered in existing literature }\end{array}$ \\
\hline H4: Premium Size & $\begin{array}{l}\text { Statutory lapse rates decrease with } \\
\text { increasing premium size (premium } \\
\text { in relation to age-average); tariff } \\
\text { switch with increasing/decreasing } \\
\text { coverage more likely for } \\
\text { policyholders with low/high } \\
\text { premium (and reversed) }\end{array}$ & Not considered in existing literature \\
\hline $\begin{array}{l}\text { H5: Individual Loss } \\
\text { Ratio }\end{array}$ & $\begin{array}{l}\text { Lapse rates decrease with increasing } \\
\text { claim reimbursement in the previous } \\
\text { year }\end{array}$ & $\begin{array}{l}\text { Results consistent with Van den } \\
\text { Berg et al. (2008), Pinquet, Guillén, } \\
\text { and Ayuso (2011), and Hofmann } \\
\text { and Browne (2012) }\end{array}$ \\
\hline H6: Age and Duration & $\begin{array}{l}\text { Decreasing lapse rates for increasing } \\
\text { age and contract duration; varying } \\
\text { effects for tariff switch }\end{array}$ & $\begin{array}{l}\text { Results for lapse consistent with } \\
\text { Strombom, Buchmueller, and } \\
\text { Feldstein (2002) and Van den Berg } \\
\text { et al. (2008) }\end{array}$ \\
\hline H7: Gender & $\begin{array}{l}\text { Female policyholders more likely to } \\
\text { lapse than male policyholders; no } \\
\text { gender differences observed for tariff } \\
\text { switching }\end{array}$ & $\begin{array}{l}\text { Results for lapse consistent with } \\
\text { Pinquet, Guillén, and Ayuso (2011), } \\
\text { Hofmann and Browne (2012), and } \\
\text { actuarial practice in Germany }\end{array}$ \\
\hline
\end{tabular}

A long portfolio affiliation does not reduce tariff switching activity to the same extent as it does for lapse activity. This likely is due to the possibility of transferring reserves to a comparable 
tariff within the company. Tariff switching is maximal for contracts with a duration of between 15 and 20 years.

\section{Gender Hypothesis (H7)}

Lapse rates for male policyholders are significantly higher than those of female policyholders. Thus our analysis reveals that policyholder gender influences lapse; however, gender does not explain tariff switch behavior. This finding is somewhat in contrast to the results of Pinquet, Guillén and Ayuso (2011), but it is in accord with actuarial practice in Germany, which uses lapse rates specific to males and females, and with the results of Hofmann and Browne (2012).

Moreover, we distinguish between lapse and statutory lapse. Our results indicate that for female policyholders, compared to male policyholders, the chance of a statutory lapse is even stronger than for regular lapse. This likely results from the fact that woman on average earn a lower income and are closer to the annual contribution limit.

Table 3 summarizes our main findings. The results for premium development, sales channel, individual loss ratio, age, duration, and gender are in line with previous findings for health insurance markets in other countries or in other insurance sectors, for example, life insurance. Moreover, we contribute new findings to the literature regarding number of premium adjustments and premium size: (1) we document a higher number of lapses in the case of fewer premium adjustments and (2) that statutory lapse rates decrease with increasing premium size. Furthermore, policyholder behavior regarding tariff switch is not considered in existing literature.

\subsection{EXTENDED MODEL WITH INTERACTIONS}

A natural extension of our analysis is to consider interaction terms in the corresponding original models. Theoretically, we can imagine relationships among our independent variables that call for consideration of how they affect lapse and switch decisions in combination. Inclusion of interaction terms, therefore, may significantly improve the quality of the model fit and, consequently, lead to more accurate results. Models with interaction terms, however, are significantly more computationally complex.

We performed several model extensions by adding one interaction term at a time from two originally incorporated categories to the original model. In each extension, the new estimates of the original categories do not vary significantly from the estimates of the model without interactions. This provides us with a robustness check of the original model fit. In three 
extensions of the lapse model, however, we observe a significant influence on the results. Specifically, in these three extensions, the parameter estimates of the interaction terms are overall statistically significant. ${ }^{12}$

Interaction between "Sales Channel” and "Premium Development (short-term)"

We incorporated an interaction term for the sales channel and short-term premium development. Overall, the regression coefficients result in odds ratios similar to those presented in Table 2. However, we obtain more detailed odds ratios for the sales channel dependent on the short-term premium development in dependence of the estimated interaction terms.

Table 4: Odds Ratios in the Model Extension with Interaction between Sales Channel and ShortTerm Premium Development

\begin{tabular}{|c|c|c|c|c|c|c|c|}
\hline \multicolumn{8}{|c|}{ Premium Development (short-term) } \\
\hline & Sales Channel & $\begin{array}{c}\text { Strongly } \\
\text { decreasing }\end{array}$ & Decreasing & Stable & Increasing & $\begin{array}{c}\text { Strongly } \\
\text { increasing }\end{array}$ & $\begin{array}{c}\text { Effect } \\
\text { w/o interaction }\end{array}$ \\
\hline \multirow[t]{2}{*}{ Lapse } & Tied agent (reference) & & & & & & \\
\hline & Broker & 1.297 & 0.658 & 1.525 & 1.602 & 1.521 & 1.525 \\
\hline \multirow[t]{2}{*}{ Statutory Lapse } & Tied agent (reference) & & & & & & \\
\hline & Broker & 0.964 & 2.854 & 1.474 & 1.375 & 1.094 & 1.341 \\
\hline
\end{tabular}

The odds ratios for brokers versus tied agents are presented in Table 4. They differ dependent on the short-term premium development. We observe that the higher lapse likelihood of brokers occurs predominantly for those policyholders with stable or (strongly) increasing short-term premium development. This result suggests that policyholders who obtained their contracts through brokers are at higher risk of lapse in the event of stable or disadvantageous short-term premium development. In the case of decreasing short-term premium development, the effect between the two sales channels is not clear. The difference between tied agents and brokers for statutory lapse vanishes in the case of extreme short-term premium development. This may be due to the fact that a statutory lapse after an extreme premium change is generally not voluntary (e.g., due to unemployment) such that a salesperson will have very little influence on contract continuation.

12 We also studied the impact of an interaction between contract duration and price change on lapse rates. Due to the usual lock-in situation in health insurance, we expect low price sensitivity expressed by low odds ratios (in case of increasing premiums) for a long contract duration compared to young contracts. However, estimates for the interaction between price change and contract duration are not statistically significant. Thus we cannot explore the lock-in effect in the considered portfolio. 
Interaction between "Sales Channel" and "Age”

The different lapse and statutory lapse rates between brokers and tied agents may also depend on the age of the policyholders, necessitating the inclusion of an interaction between sales channel and age of the policyholder. Table 5 displays the odds ratios for the sales channel dependent on the age groups.

Table 5: Odds Ratios in the Model Extension with Interaction between Sales Channel and Age

\begin{tabular}{llllllll}
\hline \multicolumn{2}{c}{ Age } & & & & & & \multicolumn{1}{c}{$\begin{array}{c}\text { Effect } \\
\text { w/o interaction }\end{array}$} \\
\cline { 3 - 8 } & Sales Channel & $(20,30]$ & $(30,40]$ & $(40,50]$ & $(50,60]$ & $(60,110]$ & \\
Lapse & $\begin{array}{l}\text { Tied agent (reference) } \\
\text { Broker }\end{array}$ & 1.266 & 1.220 & 1.593 & 1.776 & 2.226 & 1.525 \\
\hline Statutory Lapse & $\begin{array}{l}\text { Tied agent (reference) } \\
\text { Broker }\end{array}$ & 1.536 & 1.240 & 1.330 & 1.188 & 2.327 & 1.341 \\
\hline
\end{tabular}

The results for lapse suggest that the differences in the odds ratios between brokers and tied agents overall increase with the age of the policyholder. We previously hypothesized that policyholders rely on the sales representative when making decisions about contract continuation. The analysis based on the interaction model indicates that this effect is even stronger for older policyholders compared to younger policyholders. One reason may be the higher risk aversion of older policyholders (Morin and Suarez, 1983), which could intensify the influence of the sales channel on the lapse or statutory lapse decision. The effect for statutory lapse is not as obvious as for lapse.

Interaction between "Gender" and "Age"

This model extension is designed to discover if there is an interaction between gender and age. Table 6 presents odds ratios for the gender dependent on the different age groups.

Table 6: Odds Ratios in the Model Extension with Interaction between Gender and Age

\begin{tabular}{llllllll}
\hline & \multicolumn{2}{l}{ Age } & & & & & \multicolumn{1}{c}{$\begin{array}{c}\text { Effect } \\
\text { w/o interaction }\end{array}$} \\
\cline { 5 - 7 } & Gender & $(20,30]$ & $(30,40]$ & $(40,50]$ & $(50,60]$ & $(60,110]$ & \\
Lapse & $\begin{array}{l}\text { Male (reference) } \\
\text { Female }\end{array}$ & 1.450 & 1.490 & 1.188 & 1.001 & 0.916 & 1.182 \\
\hline Statutory Lapse & $\begin{array}{l}\text { Male (reference) } \\
\text { Female }\end{array}$ & 1.898 & 2.084 & 2.082 & 1.292 & 1.006 & 1.776 \\
\hline
\end{tabular}

Differences in the lapse behavior of male and female policyholders peak when the policyholders are between ages 31 and 40; differences decrease for policyholders of older ages and, in fact, 
completely disappear for policyholders older than 50. Apparently, female policyholders are more mobile in younger ages. The effects for statutory lapse are similar. Indeed, for female policyholders aged between 30 and 50, the statutory odds more than double. The gender pay gap in Germany may play a role here because if females in general earn less than males, there is a higher likelihood that females will not be eligible for private health insurance such that a statutory lapse is inevitable.

\section{CONCLUding REMARKS}

The German health insurance system requires the sale and purchase of long-term policies that yield reserves similar to those observed in life insurance and yet, unlike in life insurance, these reserves are lost to the policyholder once she or he terminates coverage with the present insurer. This situation is anticipated to affect policyholder decisions to change insurers and, possibly, their coverage. However, in the case of German private health insurance contracts written after January 1, 2009, accumulated reserve amounts are transferred to another private health insurance company in case of a lapse. This regulatory change significantly relaxes the financial lock-in effect. Our data cover decisions made prior to this legislative modification. It will be interesting to observe whether the effects analyzed in this paper change as a result. We anticipate that they will.

To understand these effects better, particularly with regard to policyholder characteristics, we analyzed two options available to policyholders of German private health insurance contracts: to lapse the contract and purchase health insurance outside the current company, or to switch insurance coverage within the current company. Using a multinomial logistic regression approach, we observe that premium development, number of premium adjustments, sales channel, premium size, individual loss ratio, and age and seniority are significant aspects influencing policyholder decisions regarding long-term health insurance contracts.

Interestingly, our analyses support some, but not all, extant empirical evidence on policyholder behavior in health insurance. Specifically, our results indicate that increasing premium development activates intense lapse and tariff switching behavior. Most likely, the relative increase in premiums compared with those of competitors is an important driver of policyholder choice. However, we have no information on competitors. 
Our results also indicate that policyholder characteristics influence lapse rates and statutory lapse rates differently. For instance, the higher the claim reimbursement in the previous year, the more unlikely is lapse and switch to another private health insurance company. However, statutory lapse is predominantly independent from claim reimbursement rates. If the claim reimbursement amount is reflecting the risk type of the policyholder, then the portfolio might be in danger of adverse selection and adverse retention. We also find a relationship between the number of premium adjustments and tariff switch rates. Infrequent premium adjustment is related to less frequent reductions of coverage; indeed, coverage enhancement is more likely in this case.

In the upcoming regulatory framework of Solvency II, the lapse module is a major risk module for private health insurance companies. Beside the risk of increasing health expenditure, the risk of a lapse decrease is the second largest underwriting risk in the calculation of the solvency capital requirement. Our results may support the private health insurance industry in determining realistic stress scenarios for lapse.

In our analysis, we used the individual claim reimbursement rate as a proxy for policyholder health status. There are, of course, more precise indicators of health status and future reimbursement amounts (e.g., diagnoses of chronic illness and information about previous operations). Future research may find it worthwhile to investigate the effect of more specific information about the health status on policyholder mobility.

\section{ACKNOWLEDGMENTS}

We thank Sandra Blome, An Chen, Lukas Hahn, Christian Kraus, Andreas Reuß, Joan T. Schmit, Hans-Joachim Zwiesler, and the participants of the $39^{\text {th }}$ Annual Seminar of the European Group of Risk and Insurance Economists for very helpful questions and comments.

\section{REFERENCES}

Altman, D., D. M. Cutler, and R. J. Zeckhauser, 1998, Adverse Selection and Adverse Retention, American Economic Review, 88(2): 122-126.

Baumann, F., V. Meier, and M. Werding, 2008, Transferable Ageing Provisions in Individual Health Insurance Contracts, German Economic Review, 9(3): 287-311.

Buchmueller, T. C., and P. J. Feldstein, 1997, The Effect of Price on Switching Among Health Plans, Journal of Health Economics, 16: 231-247.

Cochrane, J., 1995, Time-Consistent Health Insurance, Journal of Political Economy, 103(3): 445-473.

Crocker, K. J., and J. R. Moran, 2003, Contracting with Limited Commitment: Evidence from Employment-Based Health Insurance Contracts, RAND Journal of Economics, 34(4): 694-718. 
Cutler, D. M., B. Lincoln, and R. J. Zeckhauser, 2010, Selection Stories: Understanding Movements Across Health Plans, Journal of Health Economics, 29: 821-838.

Cutler, D. M., and S. J. Reber, 1998, Paying for Health Insurance: The Trade-Off Between Competition and Adverse Selection, Quarterly Journal of Economics, 113(2): 433-466.

Cutler, D. M., and R. J. Zeckhauser, 2000, The Anatomy of Health Insurance, in: A. Culyer and J. P. Newhouse, Eds., Handbook of Health Economics (Elsevier), pp. 563-643.

Davidoff, T., 2009, Housing, Wealth, and Annuities, Journal of Risk and Insurance, 76(1): 3152.

Eckardt, M., and S. Räthke-Döppner, 2010, The Quality of Insurance Intermediary ServicesEmpirical Evidence for Germany, Journal of Risk and Insurance, 77(3):667-701.

Eling, M., and D. Kiesenbauer, 2012, What Policy Features Determine Life Insurance Lapse? An Analysis of the German Market, Journal of Risk and Insurance, forthcoming.

Feldman R., M. Finch, B. Dowd and S. Cassou, 1989, The Demand for Employment-Based Health Insurance Plans, Journal of Human Resources, 24(1): 115-142.

Goldman, D. P., A. A. Leibowitz, and D. A. Robalino, 2004, Employee Responses to Health Insurance Premium Increases, American Journal of Managed Care, 10(1): 41-47.

Hendel, I., and A. Lizzeri, 2003, The Role of Commitment in Dynamic Contracts: Evidence from Life Insurance, Quarterly Journal of Economics, 118(1): 299-327.

Hofmann, A., and M. Browne, 2012, One-Sided Commitment in Dynamic Insurance Contracts: Evidence from Private Health Insurance in Germany, SSNR Working Paper (http://ssrn.com/abstract=2126953), Journal of Risk and Uncertainty, forthcoming.

Kagraoka, Y., 2005, Modeling Insurance Surrenders by the Negative Binomial Model, Working Paper.

Kuo, W., C. Tsai, and W.-K. Chen, 2003, An Empirical Study on the Lapse Rate: The Cointegration Approach, Journal of Risk and Insurance, 70(3): 489-508.

McFadden, D. L., 1981, Econometric Models of Probabilistic Choice, in: C. F. Manski and D. L. McFadden, Eds., Structural Analysis of Discrete Data with Econometric Applications (MIT Press), pp. 198-272.

Morin, R.-A., and A. F. Suarez, 1983, Risk Aversion Revisited, Journal of Finance, 38(4): 12011216.

Nelder, J. A., and R. W. M. Wedderburn, 1972, Generalized Linear Models, Journal of the Royal Statistical Society. Series A (General), 135(3): 370-384.

Pauly, M. V., H. Kunreuther, and R. Hirth, 1995, Guaranteed Renewability in Insurance, Journal of Risk and Uncertainty, 10: 143-156.

Pauly, M. V., O. S. Mitchell, and Y. Zeng, 2007, Death Spiral or Euthanasia? The Demise of Generous Group Health Insurance Coverage, Inquiry, 44(4): 412-427.

Pinquet, J., M. Guillén, and M. Ayuso, 2011, Commitment and Lapse Behavior in Long-Term Insurance: A Case Study, Journal of Risk and Insurance, 78(4): 983-1002.

Rothschild, M., and J. Stiglitz, 1976, Equilibrium in Competitive Insurance Markets: An Essay on the Economics of Imperfect Information, Quarterly Journal of Economics, 90(4): 630-649. 
Scanlon, D. P., M. Chernew, and J. R. Lave, 1997, Consumer Health Plan Choice: Current Knowledge and Future Directions, Annual Review of Public Health, 18: 507-528.

Strombom, B. A., T. C. Buchmueller, and P. J. Feldstein, 2002, Switching Costs, Price Sensitivity and Health Plan Choice, Journal of Health Economics, 12(1): 89-116.

Trigo-Gamarra, L., 2008, Reasons for the Coexistence of Different Distribution Channels: An Empirical Test for the German Insurance Market, Geneva Papers, 33(3): 389-407.

Van den Berg, B., P. Van Dommelen, P. Stam, T. Laske-Aldershof, T. C. Buchmueller, and F. T. Schut, 2008, Preferences and Choices for Care and Health Insurance, Social Science \& Medicine, 66: 2448-2459.

Viaene, S., R. A. Derrig, B. Baesens, and G. Dedene, 2002, A Comparison of State-of-the-Art Classification Techniques for Expert Automobile Insurance Claim Fraud Detection, Journal of Risk and Insurance, 69(3): 373-421. 